\title{
Entre la domesticidad y el espacio laboral: construyendo la imagen de la mujer trabajadora en el cine mexicano de la Época de Oro
}

\author{
Valentina Velázquez-Zvierkova*
}

Recepción: 10 de septiembre de 2014 Aceptación: 1 de marzo de 2017

*Ball State University, United States of America. Correo electrónico: velazquez@bsu.edu Se agradecen los comentarios de los árbitros de la revista.

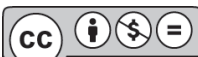

\section{Introducción}

El cine mexicano de la Época de Oro (aproximadamente 1935-1955) impulsa la imagen de un México que se moderniza. Entre los atributos que se desprenden del discurso oficial de una nación en progreso, destacan la industria próspera, la urbanización vigorosa y una clase media en ascenso, reflejados en el imaginario mexicano a través de narrativas e imágenes que proyecta el cine nacional de esta época. Jean Franco (1993: 189) sugiere que "con la modernización hay
Resumen. Se busca articular la problemática que enfrentaron las mujeres de clase media en su entrada al campo laboral en los 40 y 50 . Por medio del análisis de la construcción fílmica de la mujer trabajadora en el cine mexicano de la Época de Oro, este trabajo se enfoca en tres filmes producidos en el espacio de una década y se centra en sus estrategias discursivas y propagandísticas mientras que pretende dilucidar las limitaciones en su entrada de lleno en el terreno profesional. Estos filmes coinciden al privilegiar la domesticidad y la moral católica ante las oportunidades profesionales de las mujeres sacrificando su potencial productivo como miembros de la fuerza laboral.

Palabras clave: Época de Oro, género, modernidad, esfera laboral, domesticidad.

\begin{abstract}
Between Domesticity and Workplace: The Construction of Working Woman's Image in Mexico's Golden Age Cinema Abstract. This paper delineates the challenges that middle class women encountered in their integration to the work force during the 1940s and 1950s. It analyzes the social and artistic construction of working women's representations in Mexico's Golden Age cinema, focusing on three films produced within a decade. This work centers on the films' discursive and propaganda strategies, while seeking to ascertain the obstacles of women in their integration into the professional field. Though they range widely in perspective, these films suggest the privileging of domesticity and traditional Catholic morality over professional opportunities for women, thus limiting their potential as productive members of the workforce.
\end{abstract}

Keywords: Golden Age Cinema, gender, modernity, workforce, domesticity. 
como trabajadora, refuerza los modelos familiares en los que prevalece el orden patriarcal y redirige a la mujer hacia su rol estricto de esposa y madre.

Pese al aparente protagonismo limitado de las mujeres, la modernización de México, en particular en la capital, sí acarreó cambios significativos para ellas como resultado de la nueva movilidad laboral masiva, aunque ciertamente en menor escala que en el caso masculino. Imagining la Chica Moderna: Woman, Nation, and Visual Culture in Mexico, $1917-$ 1936, por ejemplo, Joanne Hershfield (2008) analiza algunas de las primicias para la mujer de clase media y distingue varios avances en su independencia económica, su acceso insólito a la esfera pública y la evolución del trabajo y de los espacios laborales debido a la presencia femenina. Fundamentalmente, la mujer se encontraba en transformación como sujeto social. Según Hershfield (2008: 7), “[b]roadly speaking, [la chica moderna] can be understood to encompass a set of discourses employed to describe a gendered social subject that was construed to be fundamentally different from previous categories of women by virtue of being 'modern"'.

Por otro lado, si se toma en cuenta el contexto de progreso y las ansiedades que suscita, podemos asumir que la imagen de la mujer trabajadora de clase media se construyó de forma dialéctica a partir de dos binomios latentes en el debate social sobre la feminidad: a) domesticidad/vida pública y b) modernidad/tradición. La entrada de las mujeres en la esfera pública y la consecuente modificación de los espacios laborales resultan problemáticos, puesto que repercuten en su potencial para cambiar las relaciones de poder basadas en el género. Julia Tuñón (1998: 270) señala que "en el cine mexicano el trabajo y la vida en pareja se presentan como excluyentes para la mujer, lo que obviamente no sucede con los varones". Por tanto, el debate sobre la mujer que trabaja se inscribe dentro de la división de espacios y en su capacidad de reproducción biológica por encima de las cuestiones de la división del trabajo o su potencial productivo, a diferencia del hombre. Como resultado, el discurso predominante gira alrededor de la moral y la domesticidad, y no de su potencial socioeconómico.

Si seguimos la consigna de Teresa de Lauretis de que "as social beings, women are constructed through the effects of language and representation" (1984: 14), la construcción de la mujer en la pantalla recoge los signos que circulan en el imaginario nacional sobre la feminidad, a la vez que repercute en la construcción de modelos sociales consumidos por el público nacional. Es decir, la representación fílmica se nutre de los modelos sociales existentes y los retroalimenta a través de su lenguaje visual y narrativo. Este trabajo, por tanto, analiza la representación de la mujer moderna, así como las estrategias discursivas utilizadas en tres filmes de esta época en respuesta a la profesionalización de la mujer, intentando reconciliar de modo progresivo la transición de la mujer entre los dos espacios en que opera: el doméstico y el laboral. 1

\section{En la pantalla mexicana}

El cine de la Época de Oro intentó orientar al público frente a los problemas que presenta la modernidad por medio de modelos de conducta y patrones sociales identificables para el espectador. Ana M. López (2004: 447) señala la importancia del cine en la transmisión de nuevos hábitos y códigos de conducta, "providing the new nation with the common bases and collective ties necessary for national unity. In fact, the cinema helped make a new postrevolutionary middle class viable". Carlos Monsiváis puntualiza sobre esta época del cine nacional que "en rigor, es 'la Edad de Oro' no del cine sino del público que, entre otras cosas, confía en que los ídolos le aclaren el manejo de las nuevas formas de vida, orientándolo en el vértigo de las transformaciones" (1992: 14). Por extensión, el cine responde a los debates acerca de la realidad social que desestabiliza los valores tradicionales en una nación en progreso, modeladas por los ídolos del público desde la pantalla.

El cine mexicano de la Época de Oro no se preocupa por la creación de modelos profesionales para la mujer moderna, ya que en realidad está más enfocado en reforzar los modelos familiares en que la mujer figura como madre nutricia y eje central de la familia; es decir, su interés es reafirmar los valores dominantes y no reparar ante el potencial laboral femenino. Según Monsiváis:

En la primera mitad del siglo xx, Moral es lo que admiten la Iglesia, la Familia, el Estado, la Sociedad: Inmoral es lo de fuera. [...] [A]cechan los fantasmas de la desunión: la Deshonra, el Adulterio, el Divorcio, el Grito de Independencia de los Hijos. El mensaje básico no admite controversia (si quiere, la vida moderna lo desbarata todo), pero compensatoriamente, la industria fílmica recomienda el aplastamiento del instinto y la servidumbre moral (1992: 16; énfasis original).

1. Teresita de Barbieri cuestiona las limitaciones de esta dicotomía que la crítica feminista ha utilizado por décadas. De Barbieri sugiere que estos espacios están imbricados por factores socioeconómicos y que la discusión de éstos como espacios excluyentes resulta poco productiva. Yo he decidido continuar discutiéndolos como espacios opuestos, ya que entre las estrategias fílmicas que analizo se destaca la caracterización de estos dos espacios como entidades excluyentes (2004). 
El cine se interesa en preservar el orden social, y, por tanto, las propuestas que se desvían del modelo de domesticidad, esos "fantasmas que acechan la desunión” (Monsiváis, 1992: 16), se oponen a éste; presentan el trabajo (y por extensión el feminismo) más bien como una amenaza para el modelo tradicional de la mujer o, en todo caso, como una actividad transitoria antes de llegar al matrimonio.

Esto no quiere decir que la mujer dentro del cine mexicano no ejerciera ninguna actividad económica fuera o dentro del espacio doméstico. Por el contrario, hay una variedad de cintas que reconocen el aporte de la mujer al sustento familiar y figuran entre ellas mujeres de todas clases sociales. En particular, en el caso de las mujeres de clase trabajadora, transitan en la filmografía nacional sirvientas (Calabacitas tiernas, Nosotras las sirvientas, Una familia de tantas, Ahi está el detalle), lavanderas (Nosotros los pobres, Los olvidados), costureras (Quinto patio, La mujer que engañamos) y dependientas (La gallina clueca, El baisano Jalil), y entre los oficios menos dignos abundan cantantes (Soledad, Huellas del pasado), bailarinas (Aventurera, La Reina del Trópico, Al son del mambo) y prostitutas (Santa, La mujer del puerto, Victimas del pecado, Salón México, Trotacalles).

Es prudente señalar que estas representaciones varían sustantivamente, dado el escrutinio al que están sujetas las mujeres de clase media en contraste con las mujeres de la capa trabajadora, quienes se encuentran al centro de otro discurso enaltecedor de la pobreza y de las virtudes de las capas sociales más bajas. El trabajo en el caso de estas últimas se asume como una necesidad económica que las lleva a buscar empleo para suplementar los ingresos familiares (o la falta de éstos). Con esto su imagen fílmica se construye alrededor de otros tipos de conflictos como la precariedad económica y la creación de una cultura de la pobreza. En consecuencia, el debate sobre el alejamiento del hogar en realidad no gira en torno a las mujeres de las clases populares, sino que apunta hacia la creciente clase media.

El cine nacional también ofrece representaciones de la profesionalización de mujeres de la clase media, aunque en menor escala. Hay maestras (Río Escondido, Las divorciadas, El bolero de Raquel, Muchachas de uniforme), secretarias (Nosotras las taquígrafas, La familia Pérez, Pablo y Carolina) y enfermeras (Reportaje, Mujeres que trabajan, La visita que no tocó el timbre) y con menos frecuencia, pero no siempre en el rol protagónico,

2. Julia Tuñón utiliza el término deber ser a lo largo de Mujeres de luz y sombra en el cine mexicano: la construcción de una imagen (1934-1952) para designar las conductas que se esperan de la mujer, correspondientes a la ideología dominante sobre la construcción de la imagen femenina y la familia mexicana en la pantalla grande (1998). las profesionistas (Nocturno de amor, María Candelaria, La casa chica, Arriba las mujeres, El monstruo resucitado). Sin embargo, es común que estos filmes, lejos de celebrar la participación de la mujer en la economía, cuestionan su feminidad, su alejamiento del seno familiar y su rol como madre y esposa, o lo que Adrienne Rich denomina el llamado sagrado (sacred calling) (1986: 43).2

Entre los varios filmes de esta prolífica época en que hace aparición la mujer trabajadora, destacan en particular la comedia Arriba las mujeres (1943), de Carlos Orellana, y los melodramas Nosotras las taquígrafas (1948), de Emilio Gómez Muriel, y Mujeres que trabajan (1953), de Julio Bracho. Producidos en un espacio de diez años, estos proyectos comerciales de entretenimiento estaban dirigidos básicamente hacia un público femenino, ya que no pretendían generar un mensaje emancipador para la mujer ni cuestionar el orden social al que estaba sujeta. Sin embargo, resultan valiosas para el análisis de la construcción femenina en el cine puesto que responden de manera directa a la incursión de la mujer en el espacio laboral y, en menor medida, al feminismo incipiente en los 40 y 50 . Estos tres filmes se destacan entre la filmografía de la Época Dorada dado su enfoque en el conflicto sobre el acceso al trabajo y sus repercusiones en las relaciones de poder. Asimismo, cada una de las cintas corresponde a distintos géneros fílmicos (comedia, melodrama y noir), por lo que abordan la problemática desde perspectivas concretas, y gradualmente hacen ostensible la aceptación de las mujeres en el campo laboral.

\section{Arriba las mujeres (Carlos Orellana, 1943)}

La comedia Arriba las mujeres, de innegable corte popular, ofrece una sátira sobre el feminismo. La narrativa es presentada desde la perspectiva de don Laureano (Carlos Orellana), un hombre provinciano que va desde Chihuahua hacia la capital con su hija Chole, una joven mujer sencilla, trabajadora, pero carente de sofisticación. Laureano quiere que sus compadres Próspero (Joselito Rodríguez) y Felicidad (Consuelo Guerrero de Luna) la instruyan, que aprenda bordado y pastelería fina, como sus hijas. Chole se equivoca y dice que va a la capital para que la "destruyan", haciendo preámbulo de su formación feminista y consecuente alejamiento del modelo tradicional femenino. La narrativa se polariza en términos de los ejes espacial y temporal, y yuxtapone la modernidad con la tradición cuando se colocan en un extremo la capital ligada a ésta y en el extremo opuesto la provincia asociada con lo arcaico. La capital, fuente inagotable para la mitología divulgada por el cine mexicano (Monsiváis, 1992: 14-15), se representa como el centro de 
la modernidad y la prosperidad mexicanas, pero también como espacio de deterioro de la familia, tema recurrente en el cine que idealiza el campo como bastión de la tradición y la mexicanidad.

Al llegar a la casa de los compadres, Laureano los encuentra irreconocibles, Felicidad se ha convertido en abogada y es presidenta de la Liga de las Camisas Pintas y directora del Partido Socialista Feminista. El compadre en cambio asume los roles domésticos de administrar la cocina, la lavandería y a la servidumbre, es decir, la familia se encuentra en desorden y los roles de género se han invertido por medio de la división del trabajo. Al contrario de las expectativas de Laureano de encontrar a las hijas decorando pasteles, las hijas son profesionistas: Amalia es médica y Luz Tenue es pintora. Los rótulos de sus despachos anuncian "Abogado", "Médico" y "Pintor", respectivamente, además de que las hijas usan pantalones y Felicidad, saco sastre y corbata. La cinta señala por medio de estos dispositivos visuales que la trasgresión de sus roles asignados se representa de modo simbólico por la apropiación de elementos masculinos correspondientes a la identidad profesional y la ropa. En consecuencia, la identificación de las tres mujeres con sus profesiones tiene un efecto masculinizante. El tema principal del filme es en esencia la recuperación de los roles genéricos, el retorno a los puestos tradicionales para los hombres y las mujeres, y así lograr la restauración del orden familiar por medio del matrimonio y la maternidad de las hijas, para lo cual debe sacrificarse la profesionalización que habían alcanzado.

La parodia en este filme abre las posibilidades para la crítica al feminismo, sobre todo por el ingreso de las mujeres en el ámbito laboral mediante el cual adquieren autonomía y se independizan del hombre (o incluso lo subyugan). La Liga predomina sobre el ambiente familiar y Felicidad proclama: "Un hogar donde no domine completamente la mujer es un hogar perdido". En contraste con su nombre, Felicidad crea el sufrimiento en su esposo Próspero: "Es como para echarse a llorar esto que me ocurre. Mi mujer y mis hijas, no conformes con ejercer profesiones masculinas, pertenecen a la Liga de las Camisas Pintas. Son las directoras del Partido Socialista Feminista". En cambio, el ideal femenino de Próspero es la provinciana Chole, apegada al modelo femenino tradicional:

Próspero: ¡Qué mansedumbre! Esto sí es una mujer. Hace mucho tiempo que no veía yo un alma ingenuamente femenina. Qué diera yo porque mis hijas fueran así.

Laureano: ¿Apoco le gustaría que sus hijas fueran como mi Chole? Próspero: Así, rancherita, inocentona, sonsa si usted quiere, pero encantadoramente femenina (minuto 10:53).
La idealización de la mujer provinciana, que proviene del paraíso rural, según diría Monsiváis (1992), niega la inteligencia de las mujeres a favor de un modelo femenino que la mantiene subyugada, tonta pero obediente.

La postura hembrista de la Liga de las Camisas Pintas fracasa en su intento de subordinar al hombre debido a que la subyugación de éste es su único propósito y no la igualdad entre géneros. Próspero explica que perdió el control sobre Felicidad años atrás cuando lo descubrió en un acto de indiscreción. Según Julia Tuñón (1998: 167), “el feminismo es, en [Felicidad], una táctica, no una finalidad". El filme acude al estereotipo de la mujer humillada que se venga del hombre, pero no le permite motivos más elevados, ya que no se trata de un poder que Felicidad gana, sino un puesto que Próspero pierde mediante la infidelidad. Contrario al discurso evidentemente paródico de la Liga de las Camisas Pintas, el trabajo se convierte en un instrumento para lograr la venganza y se privilegia ante la búsqueda de la emancipación o la agencia femenina.

Por consiguiente, es la transgresión moral del esposo lo que desestabiliza el hogar y altera los roles de género; sin embargo, existen dos factores que ejercen el retroceso para recuperar el lugar tradicional: la visita de Laureano (portador de la tradición) que funciona como catalizador para recuperar el lugar de Próspero y el deseo de las hijas, y por extensión las otras mujeres de la Liga y el público femenino al que se dirige el filme, de convertirse en esposas y madres. La autonomía obtenida mediante su profesionalización cede ante el prospecto de una vida feliz en el matrimonio y la maternidad. Una a una, las mujeres de la Liga abandonan a Felicidad. Finalmente, ésta reconoce su error y retorna a su lugar de subordinación ante Próspero, disolviendo así la Liga de las Camisas Pintas y renunciando a su postura de poder. La labor femenina en este filme se trivializa sin trascender más allá del pretexto para subvertir las relaciones de poder entre géneros.

\section{Nosotras las taquígrafas (Emilio Gómez Muriel, 1950)}

El melodrama Nosotras las taquígrafas se basa en la novela homónima de Sarah Batiza, publicada en 1950, y presenta los sucesos cotidianos en una oficina donde trabaja una decena de taquígrafas, en su mayoría solteras y algunas con miras al matrimonio con los ejecutivos de la empresa. El filme hace hincapié en las relaciones sentimentales y en los efectos del espacio laboral sobre los deseos de hombres y mujeres. El eje narrativo se enfoca en una taquígrafa novata, María Eugenia Blanco (Alma Rosa Aguirre) y su enamorado David Martínez (David Silva), un vendedor máquinas de escribir eléctricas. Echando mano de las convenciones temáticas y formales 
propias del melodrama, Nosotras las taquigrafas articula por esta vía el debate sobre la profesionalización de la mujer y las consecuencias sociales resultantes de esta transición. En su libro Pragmatic Passions: Melodrama and Latin American Social Narrative. Matthew Bush (2014: 14-15) indica que:

melodrama functions not only as a mode for comprehending dramatic action in a given text, but also as a modern means for understanding social and historical processes that are too abstract to grasp in any sort of quantitative manner. Melodrama thus provides a narrative structure that facilitates an understanding of the social.

De igual forma, el filme se estructura alrededor de la narrativa sentimental que, como marco referencial para un público femenino, sirve de contexto para el entendimiento de nuevos temas que llegaban con la modernidad a México, tales como la rivalidad profesional, la autonomía de la mujer, la madre soltera y el suicidio.

El filme abre con una voz en off sobre un montaje que proyecta decenas de empleados entrando a un edificio. Entre apretujones, prisas, columnas y escalinatas, la cámara se enfoca en María Eugenia en su primer día:

A las mujeres que trabajan está dedicada esta historia. [...] Pero principalmente a la que se inicia, a la que desconoce el ambiente de la oficina. [...] Las mujeres que trabajamos participamos de muchas vicisitudes. [...] ¡Cómo se nos critica y condena! Y qué poco se nos conoce y se nos comprende (minuto 2:28).

Termina la narración en off y María Eugenia se persigna antes de ingresar en la oficina. El preámbulo va dirigido a las taquígrafas novatas como ella, a las mujeres jóvenes que inician su vida laboral dentro del ambiente de las oficinas. El espacio que cruza María Eugenia es intimidante -columnas gruesas de piedra y corredores amplios e interminables-y se presenta amenazador, frío, inhóspito, contrastando con el espacio doméstico que comparte con su madre. El acto de persignarse se presta a una doble lectura. Primero, siguiendo las imágenes visuales, María Eugenia se detiene ante este espacio y requiere de la disposición divina para penetrarlo. La segunda lectura de su gesto coincide en paralelo con el final de la narración extradiegética que la advierte de las críticas a las taquígrafas, de las injusticias y condenas para las mujeres que trabajan ("“Cómo se nos critica y condena!”). Las historias desarrolladas alrededor de María Eugenia funcionan como un modelo o guía para entender las dinámicas del ambiente laboral, pero más allá del sentido práctico, advierten a la mujer joven de los peligros y tentaciones a los que está expuesta en el trabajo, lo cual remite invariablemente a las relaciones de género y a las relaciones sentimentales y sexuales.

Entre las historias que presenta el filme, la más dramática es la de Elsa, quien sostiene una relación con el licenciado Gálvez (Eduardo Noriega), pero cuando ella le revela su embarazo, él se niega a casarse. Elsa intenta suicidarse y en su estupor es atropellada por un auto, pierde al hijo nonato y al poco tiempo ella muere también. Bajo una lectura alegórica (Lahr-Vivaz, 2016: 14-15), el modelo de Elsa como madre soltera está condenado al fracaso. Las muertes de Elsa y de su hijo se presentan como recurso propagandístico del filme. Como señala Simone de Beauvoir en The Second Sex, "the unwed mother is a scandal to the community, and illegitimate birth is a stain on the child" (1968: 696). Así pues, el filme establece la consecuencia fatal por no conformarse a los límites sociales tradicionales para la mujer: no permite el nacimiento del hijo ilegítimo ni perpetúa en su persona el legado de una relación ilícita.

El filme no muestra un tema nuevo al presentar la idea de la mujer seducida y después abandonada, pensemos en Santa de Antonio Moreno (1931), por ejemplo. Sin embargo, ofrece dos primicias; por un lado, dirige una advertencia a las mujeres jóvenes que por primera vez se ven expuestas al ámbito laboral por su vulnerabilidad antes hombres depredadores como Gálvez y por su alejamiento de la figura protectora del padre y, en segunda instancia, el filme presenta el suicidio como alternativa para la maternidad en la soltería, problematizada por la falta de apoyo económico y social a pesar del trabajo asalariado. En este sentido, el concepto de la reproducción en la mujer prevalece por encima de su capacidad como trabajadora, como mujer independiente y productora, y por el contrario explota el potencial sentimental y moral y limita a la mujer al modelo tradicional de María Eugenia como paradigma femenino aceptable mientras que condena a Elsa por su fracaso moral.

La voz en off cierra el filme y reitera el mensaje redentor de la mujer trabajadora:

Taquígrafas, ni culpables ni inocentes, sencillamente mujeres, mujeres que contribuyen en el modesto plano de su trabajo al progreso universal. A veces les atrapa la pasión entre sus mallas o el amor las olvida injustamente, pero su presencia dulcifica la tarea de ganar el pan. Son flores en el hogar, en la oficina y en la vida (minuto 1:39:30).

Se reduce a las mujeres a un rol pasivo, ornamental y nutricio dentro del "progreso universal", así como reproduce la visión patriarcal del discurso oficial y limita la problemática de la mujer trabajadora al plano de la moral. De manera simultánea le niega el rol activo dentro de este progreso. 


\section{Mujeres que trabajan (Julio Bracho, 1953)}

Mujeres que trabajan se estrena en 1953 y coincide con la llegada del sufragio femenino a México. La labor artística del director Julio Bracho es de amplio reconocimiento por su estética y conceptualización de temas polémicos. Su filmografía oscila entre el cine comercial y un cine artístico e intelectual. Mujeres que trabajan, melodrama de corte noir, no figura entre sus filmes más memorables; sin embargo, en él gira la polémica en torno a la independencia de la mujer. La cinta incluye varias actrices reconocidas, acaso inspirada en el filme norteamericano The Women (1939), dirigido por George Cukor, y que anunciaba un elenco completamente femenino: "With a cast of 135 women. Women, Women, Everywhere, and not a man in sight! 'The Women' (and it's all about men)" (minuto 0:13). La crítica contemporánea (Rafael Solana en García Riera, 1986: 279) recibe Mujeres que trabajan favorablemente: "Si sus más recientes producciones apuntaban ya a ese blanco [el público femenino], esta vez ha acertado al centro".

La secuencia inicial del filme presenta un montaje de estilo documental de mujeres trabajando: oficinistas, obreras, cultoras de belleza, modistas; mujeres que rinden testimonio a la participación femenil en distintas labores durante esta época de desarrollo económico e industrial. El montaje crea una sensación de extrañamiento al mostrar escenas del trabajo cotidiano, pero reapropiadas por la presencia femenina y que suprime la masculina, al estilo de Cukor. Este preámbulo presenta el espacio laboral como una esfera donde la mujer se desenvuelve con naturalidad, sin cuestionar su pertenencia, y exalta su aporte al progreso mientras desplaza al hombre fuera de la actividad económica.

El formato del filme se inspira en el cine policíaco, pues abre la narrativa con la secuencia de un asesinato. Se trata de un crimen pasional explicado a través de un largo flashback que se cierra hacia el final del filme. La trama de Mujeres que trabajan gira alrededor de dos historias entrecruzadas. Son los dramas de dos mujeres que trabajan, pero que representan modelos opuestos de feminidad: la mujer tradicional y la mujer moderna. La primera es la historia de Isabel (Columba Domínguez), una joven soltera que llega a la capital desde Guadalajara después de que su padre la ha expulsado del hogar debido a su embarazo. Isabel se instala como institutriz por medio de la agencia de colocación de Laura (Andrea Palma) y se aloja en la casa de huéspedes de la señorita Benavides. Isabel es, sin duda, un personaje paradigmático: la mujer mexicana de provincia, receptora y portadora de los valores tradicionales; no obstante, es castigada con la expulsión del seno familiar a raíz de su transgresión.

La segunda historia es la de Claudia (Rosita Quintana), otra inquilina en dicha casa para señoritas, que a diferencia de las demás mujeres es la dueña de Casa Claudia, una casa de modas de mucho éxito, y es la más solvente de todas, "la Perla de la Casa", según sus compañeras. Claudia, autoritaria y autosuficiente, demuestra una actitud negativa ante el amor y los hombres, y que rechaza la idea del matrimonio. Ignorante de la condición de Isabel, Claudia le aconseja:

\begin{abstract}
No se deje engañar, juna mujer vale tanto como un hombre! Haga su vida por sí misma, consiga una posición. ¡Trabaje! Sólo entonces, y si usted es tan tonta para creer en las palabras de un hombre, pues hágale caso al primero que pase. Será lo mismo, todos son iguales, pero eso sí, podrá tratarlos de potencia a potencia. En estos tiempos las mujeres tenemos que ser más fuertes que nunca (cronometraje no obtenido).
\end{abstract}

Contrario a Isabel, la hipervigilancia de su castidad no corresponde tanto a las convenciones sociales de la moral como a sus valores personales. Rehúye a las relaciones sentimentales no por miedo de la deshonra hacia el padre o la familia, sino porque teme las consecuencias para su desenvolvimiento individual. ${ }^{3}$ Claudia afirma: "Lo difícil no es vencer a los hombres, sino a sí misma, y el trabajo nos ayuda. Valemos más que ellos y podemos vivir solas". A diferencia de Isabel, Claudia sólo se debe esta responsabilidad a sí misma. Desarrolla su agencia a través de su ética de trabajo y no considera el matrimonio un llamado noble, sino una carga para la mujer.

Mujeres que trabajan reitera la problemática del abandono del espacio doméstico, es decir, la tensión de nuevo reside en el binomio tradición/modernidad, como en los dos filmes anteriores. El filme aprovecha los signos asociados por el público para representar la provincia (Isabel) como símbolo de la tradición y el pasado, y la ciudad (Claudia) como espacio de modernidad que cuestiona la tradición como una limitante para el desarrollo de la mujer. De esta manera, se contraponen los valores asociados a la familia y al pasado, en oposición a la autonomía y el éxito profesional de la mujer dentro de la modernidad. Esta contraposición acentúa el debate cuando se entrecruzan las historias de Isabel y Claudia. En un principio la situación de Claudia, la mujer que trabaja, es de privilegio en comparación a la incertidumbre de Isabel, la mujer vulnerada por quebrantar su rol tradicional.

3. La caracterización de Claudia coincide en cierto grado a la de Joan Crawford en Mildred Pierce (Michael Curtiz, 1945), en que hace su fortuna mediante su cadena de restaurantes. Además de la primicia del modelo de la self-made woman, éste responde a los modelos femeninos acostumbrados en el cine mexicano por su adhesión a las profesiones femeninas. 
Sin embargo, la renuencia de Claudia eventualmente es vencida cuando la seduce Alfredo (Alberto Carrier), por lo que cambia su perspectiva sobre los hombres y modifica su percepción negativa ante las expectativas tradicionales de su género. La trama se intensifica cuando Claudia descubre que Alfredo no planea dejar a su esposa millonaria y que también es el padre del hijo de Isabel (el hombre que la sedujo y abandonó), es decir que, a pesar de su movilidad social, no logra trascender su vulnerabilidad en el terreno de la diferencia sexual y continúa presa del deseo masculino. El puente entra ambas historias (Isabel y Claudia) es, entonces, Alfredo, quien traspasa estas divisiones de la provincia y la ciudad, el pasado y la modernidad, y vulnera tanto a la mujer tradicional como a la mujer moderna por igual.

Claudia asesina a Alfredo y posteriormente es arrestada y enjuiciada, lo cual da lugar a un careo que funciona como plataforma para el debate entre la emancipación de la mujer y su supuesta pertenencia al espacio doméstico. El juez le advierte:

He visto muchas mujeres como usted detrás de estas rejas. Conozco el tipo: mujeres emancipadas que viven solas, creyendo bastarse a sí mismas, despreciando la santidad de un hogar, la protección de un hermano, quizá de un padre. No todos los hombres son iguales y ese hermano o padre hubieran podido ampararla y defenderla. Pero usted no los quiso a su lado, prefirió vivir sola (cronometraje no obtenido).

Sin embargo, interviene Isabel al responder que ella es la hija del juez (otra coincidencia existente sólo dentro de la lógica del melodrama): "Cuando más falta me hizo la comprensión y el perdón de los demás, no lo encontré en mi propio padre". Por su propia falla moral, el juez es a la vez sometido a una valoración en la que representa no sólo a la justicia, sino en un nivel simbólico, al Estado paternal. La crítica del filme escala al nivel de lo institucional: destaca la sujeción de la mujer a la doble moral de la sociedad y del Estado que define las normas que determinan el fracaso de la mujer en su avance social.

Durante el juicio Claudia expone las razones para asesinar a Alfredo:

Yo no maté a Alfredo Bergman. Maté en él a todos los hombres que, riéndose de su hazaña, caminan impunemente por las calles y matan el amor y la vida de las mujeres. He matado a los hombres que juegan con nuestras vidas sin siquiera tener conciencia y dolor de que destruyen lo más grande y noble que es nuestra conciencia y responsabilidad (cronometraje no obtenido).
Se establece, entonces, que el problema femenino no sólo consiste en la sujeción de la mujer a uno u otro espacio, o su adherencia a los valores tradicionales frente a la autonomía femenina en la modernidad, sino en la vulnerabilidad social de la mujer, la falta de apoyo y protección, de garantías y derechos, problema que trasciende lo personal y se arraiga en las instituciones sociales. Claudia finalmente se rinde ante la justicia patriarcal, una justicia que "no ampara a las mujeres burladas". A pesar de la aparente falta de dimensión política, el filme sí encara la problemática de la mujer, pero no lo hace en un contexto laboral o legal sino privado. Ignacio Sánchez Prado (2014) explica que "historically, melodrama was a cultural form, which allowed Mexican audiences the negotiation of social inequality through narratives that tied emotion and love to social redemption". Con esto, el filme no defiende la postura de la mujer por la capacidad productiva y su potencial económico, sino que desplaza el debate de lo laboral al eje de lo personal, es decir, al plano afectivo.

La crítica contemporánea reacciona a partir de perspectivas divergentes. En su mayoría las reseñas muestran complacencia por la defensa de la mujer. Rosario Vásquez Mota apunta en su reseña fílmica para La Afición en 1953, año de estreno de la cinta:

Interesante y atractiva, en general, especialmente para las mujeres. Y para los hombres también a quienes se les da una sonora catilinaria. [T] oca un problema social palpitante en nuestro medio: el de las madres solteras, consecuencia de la irresponsabilidad masculina como padres y como puntales de la integración y superación de la familia (en García Riera, 1986: 279).

Por contraste, Arturo Perucho para El Nacional, elogia la calidad del filme y la actuación en general; sin embargo, señala que "lo peor es el argumento; y lo peor del argumento, esa ridícula escena final, en que Rosita Quintana 'suelta' un discurso de sufragista trasnochada contra la maldad de los hombres" (en García Riera, 1986: 281). Perucho invalida la denuncia articulada en el filme y recurre al estereotipo antifeminista, similar al que registra Arriba las mujeres. Más inquietante aún resulta la crítica de El Duende Filmeo en El Universal, de la que destacan las siguientes líneas y ligeros matices de misoginia: "Pero ni todos los hombres son tan malos, ni todas las mujeres tan fáciles de seducir como la vemos en esta cinta y si Báez, Eis, Alejandro y Bracho, se han constituido en terribles acusadores de los hombres no hay que olvidar que, según Nietzsche, la mujer fue el segundo error de Dios" (en García Riera, 1986: 281). 


\section{Moral, domesticidad y el trabajo (re)productivo}

En el debate público sobre la entrada de las mujeres de clase media al ámbito laboral prevalece el discurso patriarcal por sobre las implicaciones laborales o de derechos de la mujer. ${ }^{4}$ Simone de Beauvoir (1968: 682) advierte esta diferencia:

The woman who is economically emancipated from man is not for all that in a moral, social and psychological situation identical with that of man. The way she carries on her profession and her devotion to it depend on the context supplied by the total pattern of her life.

La mujer debe hacerse cargo del espacio doméstico y la maternidad pese a su desempeño laboral, que se registra desde finales del siglo XIx (Hershfield, 2008; Tuñón, 1998). La mujer no puede integrarse al trabajo de la misma manera que el hombre, dado que su contexto y patrón de vida difieren en tanto su capacidad reproductiva y la carga moral asignada a ella. Según Tuñón (2015: 129):

El trabajo de la mujer suscita todavía más discusiones. Al ser ellas definidas por un cuerpo potencialmente materno, sus labores deben dirigirse al bienestar de la prole y del marido, su espacio ser exclusivamente el doméstico, deben quedar exentas de cualquier sospecha de ambición, quedar satisfechas dentro de los límites de una casa, manteniéndola en orden y dando sustento, sin revolver ni trastocar las estructuras sociales.

El debate nacional, trasladado a la sala de cine en estos años, privilegia la discusión sobre la subordinación de la mujer y sus obligaciones familiares. El espacio doméstico adquiere un lugar central en varias cintas. Basta recordar Cuando los bijos se van (Juan Bustillo Oro, 1941), uno de los filmes más emblemáticos al respecto, en donde el hogar funciona como lugar de resguardo y donde la moral porfiriana protege a los hijos de los peligros de la modernidad. En alusión a este tema, Carl J. Mora (2005: 56) indica que "disaster invariably comes to any of [the family] members who seek to break their bonds with the sacrosanct family and it is only when they have rejected the world outside and all personal ambition that they find security". Para el cine mexicano, por lo tanto, el modelo social apunta no hacia el éxito profesional, sino hacia la integridad de la familia a costa del éxito individual.

El hogar también tiende a extenderse y en ocasiones a confundirse con el espacio laboral. En el caso de Arriba las mujeres toda la actividad económica se concentra en la casa, de puertas hacia adentro. Asimismo, el fracaso de Felicidad y sus hijas se manifiesta no sólo como feministas, sino también como profesionistas por su incapacidad de atraer clientela, y deben desistir en el intento de ejercer sus profesiones. Claramente, las limitaciones de la comedia imposibilitan atender todas las dimensiones del feminismo; sin embargo, dentro de las contradicciones en la construcción de estos personajes resalta la inercia que las mantiene en el hogar y su consecuente incompetencia profesional que las orilla finalmente a aceptar sus roles femeninos tradicionales y a abandonar la vida laboral.

En Mujeres que trabajan la casa de huéspedes hace las veces de hogar, incluso para Claudia. Con la fortuna que ha acumulado como producto de su vida profesional, ha reconstruido su departamento de lujo, adentro de la casa de huéspedes en vez de comprar un espacio separado. Asimismo, Casa Claudia permanece cerrada a la presencia masculina. Se trata de un establecimiento en el que modistas, ayudantas, modelos y clientas nutren el espacio con la presencia exclusivamente femenina. En adición, el nombre mismo de esta entidad, Casa Claudia, hace una referencia al espacio doméstico. Dado lo anterior, el espacio laboral se convierte en una extensión del espacio doméstico, y la intrusión del hombre constituye la ruptura de los valores que hay que salvaguardar.

De los tres filmes, únicamente Nosotras las taquigrafas hace una distinción entre el espacio doméstico y el espacio laboral. Sin embargo, el filme contrasta la naturaleza de los hogares de María Eugenia y Elsa. María Eugenia vive con su madre, por tanto, su adhesión a los valores provincianos y la cercanía entre ellas son los dos factores que protegen su reputación y la llevan al matrimonio con David. Por el contrario, Elsa comparte un departamento con su hermana, otra mujer trabajadora, pero sin la presencia de una figura de autoridad masculina. El espacio doméstico no invade el laboral, sino a la inversa, la actividad económica y la consecuente independencia determinan las cualidades del espacio doméstico y la calidad moral de estas mujeres. En el caso de Elsa la falta de modelos de autoridad corresponde con su debilidad moral y su muerte eventual. En cambio, la autonomía de María Eugenia corresponde a las expectativas de la "decencia" mexicana cuando su conducta se ve mediada por la presencia de la madre y los cuidados del futuro esposo.

Teresita de Barbieri (2004: 200) condensa las dos líneas teóricas principales para el entendimiento de la subordinación de la mujer al espacio doméstico. La primera es la línea marxista que "hace depender los sistemas de género de la división social del trabajo según los sexos", mientras que la segunda línea de pensamiento:

\footnotetext{
4. Entre los temas de contención, al centro se encuentran el derecho al voto y la representación femenina en sindicatos textiles y asociaciones como la Confederación Revolucionaria de Obreros y Campesinos (CROC), la Confederación de Trabajadores de México (СтM) y la Confederación Regional Obrera Mexicana (CROM) (IEESA, 2012: n.p.).
} 
ubica el núcleo del conflicto originado en la capacidad exclusiva de los cuerpos femeninos de producir seres humanos de ambos sexos. Para obtener el mayor control posible sobre la capacidad reproductiva se ha requerido controlar también la sexualidad y la capacidad de trabajo de las mujeres.

Ambas líneas de pensamiento coinciden en la capacidad de trabajo como elemento fundamental de su dominación y que se integra en la división de labores como parte de ese control de género. Tal división, como ya la ha discutido la teoría (desde Marx, Engels, Rubin), inscribe el trabajo doméstico en el sentido que aporta a la productividad a través de la producción de bienes y el establecimiento de relaciones que apoyan dicha producción. Al mismo tiempo, el resguardo de la reproducción del cuerpo de la mujer es vital, ya que el cuerpo genera a su vez la reproductividad de la fuerza laboral. Ambos conceptos, el trabajo doméstico y la reproducción de la mujer, se controlan a partir de su dominación que se regula a través de la moral.

En el caso del México de mediados de siglo xx, la moral católica, al igual que los valores socioculturales correspondientes a las diversas clases sociales, se encontraba en la base de los debates en torno a la mujer. El dogmatismo religioso y sumisión ante la autoridad patriarcal se transfieren a la sala de cine. En Arriba las mujeres la capacidad reproductiva de las hijas de Felicidad y su deseo de ser madres constituyen el catalizador que las lleva a su rompimiento con las ideas feministas de la madre y a dejar sus profesiones supuestamente masculinas. La concepción de la moral es más ambigua en este filme por tratarse de una comedia; en cambio, reduce sus preocupaciones al retorno correspondiente de los hombres y las mujeres a su lugar. En Nosotras las taquigrafas y Mujeres que trabajan el terreno de lo moral es más evidente. Las transgresiones colocan a las mujeres en situaciones precarias que culminan incluso en la muerte. El embarazo de Elsa se resuelve con la pérdida del hijo, y elimina así la maternidad de la soltera, mientras que su propia muerte la redime por su trasgresión. El embarazo de Isabel, por otro lado, es redimido por Claudia con la muerte de Alfredo, y Claudia a su vez es castigada por el Estado (la autoridad patriarcal).

Resulta con esto interesante la opinión del público, como se observa entre las cartas recibidas en respuesta a la campaña publicitaria para Mujeres que trabajan. Entre estas cartas destaca la de la señora Adela Formoso de Obregón Santalicia, directora general de la Universidad Femenina, dirigida al director de Cinematografía de la Secretaría de Gobernación. En ella, la directora cuestiona la decisión de la clasificación del filme:
La película Mujeres que trabajan afirma mi lucha de años, de exigir las leyes de protección a la infancia y a la adolescencia; porque con ellas se protegerá a la mujer que trabaja, a ella que está expuesta a todas las ambiciones y a todos los apetitos de hombres sin conciencia, sin responsabilidad, sin calidad humana y sin pudor. Las palabras de la mujer condenada me trajeron a la conciencia y a la memoria la terrible tragedia que padecen las mujeres por ser mujeres, por no tener protección. A muchos hombres con un complejo de machismo no les importa destruir al corazón y a la vida humana de esa mujer sin protección (en García Riera, 1986: 82; énfasis propio).

La autora de la misiva articula su crítica a la inequidad de género y aborda el tema de la defensa de la mujer a partir de su vulnerabilidad por su rol reproductivo. Señala el abuso derivado del machismo y recalca la responsabilidad del Estado en torno a la mujer en el contexto laboral. Llama la atención también la incorporación del cine dentro de su marco referencial para proponer el cambio legislativo a favor de la mujer, es decir, la manera en que la función del cine traspasa los límites del entretenimiento y lo artístico hacia la arena de lo político.

\section{Conclusiones y análisis prospectivo}

En el cine de los 40 y 50, la conceptualización del modelo anquilosado de la mujer de clase media privilegia la elección del matrimonio y la maternidad por sobre su incorporación en la esfera laboral, es decir, contradictorio a las fuerzas sociales que amenazaban con alterar el espacio en los que se desenvolvía la mujer y dentro del amplio contexto del nacionalismo mexicano. Los tres filmes discutidos representan los cambios vertiginosos que genera el crecimiento de la economía mexicana de mediados del siglo xx y responden a la incorporación de la mujer en el trabajo; generan una propaganda adversa a su participación y articulan una serie de advertencias sobre los peligros y tentaciones a las que queda expuesta por su alejamiento del espacio doméstico y el abandono de sus roles tradicionales de esposa y madre.

Arriba las mujeres y Nosotras las taquígrafas articulan una respuesta frontal a estos cambios y presentan la felicidad de la mujer, derivada del matrimonio y la maternidad, y su profesionalización como categorías mutuamente excluyentes, posicionando el orden moral al centro del discurso sobre la mujer y la nación. Por contraste, si bien Mujeres que trabajan de Julio Bracho no genera un modelo alternativo en respuesta a las limitaciones sociales reflejadas en el filme, sí elabora una reflexión en torno a la responsabilidad social del hombre y el Estado dada la relación vertical entre los géneros. 
También el modelo doméstico falla en este filme y debe intervenir el Estado para castigar el distanciamiento de la mujer del seno familiar, equiparado en este caso al acto criminal. Por tanto, ninguno de estos tres filmes aboga por la autonomía de la mujer o su completa integración en el espacio laboral. Sin embargo, a pesar del impulso propagandístico, correspondiente al discurso oficial, estos filmes abren un espacio de debate desde diferentes perspectivas en torno a la mujer trabajadora y marcan un progreso en la transición para la mujer del hogar al espacio laboral.

Este trabajo busca dar un paso dentro del estudio de las representaciones fílmicas atípicas de la mujer en el cine mexicano de la Época de Oro. Si bien la participación en el cine mexicano de la época dorada, directores como Julio Bracho presentaron propuestas novedosas en torno a la mujer, el corpus predominante de la filmografía mexicana reitera los modelos tradicionales a los que ésta debía apegarse. Con el declive de la época dorada, la representación de la mujer trabajadora en el cine mexicano comercial se mantuvo virtualmente inalterado. Filmes como Muchachas que trabajan
(Fernando Cortés, 1961) y otros tantos en los que figura la mujer profesionista dieron continuidad a los ya ensayados paradigmas conservadores en torno a la mujer joven, futura madre y esposa.

Dentro de un enfoque prospectivo, resultaría productivo establecer diferentes líneas de investigación en varias direcciones. Rompiendo con el modelo de la maternidad obligada, ¿en qué momento dentro de la cinematografía mexicana se suma la imagen de la mujer trabajadora independiente?, ¿cuál es la representación de la mujer trabajadora desde la perspectiva de las directoras de cine?, ¿qué tipos de modelos de la mujer trabajadora existen en el cine contemporáneo?, ¿cuál ha sido la recepción del público ante los modelos de la mujer trabajadora? A partir de este cuestionamiento de múltiples perspectivas, sería posible ampliar la investigación sobre la configuración de los modelos femeninos en el cine y sobre las actitudes generales ante la mujer en el campo laboral. De esta forma, se podrían desarrollar teorías sobre la porosidad del cine en relación con los cambios sociales y económicos que presenta a su público.

Referencias

Barbieri, T. de (1991). Los ámbitos de acción de las mujeres. Revista Mexicana de Sociología, 53(1), 203-224.

Barbieri, T. de (2004). Más de tres décadas de los estudios de género en América Latina. Revista Mexicana de Sociología, 66, 197-214.

Beauvoir, S. de (1968). The Second Sex. London-Nueva York: The Modern Library.

Bracho, J. (director). (1953). Mujeres que trabajan (película). Agrasánchez Film Archives, 1998.

Bush, M. (2014). Pragmatic Passions: Melodrama and Latin American Social Narrative. Madrid-Frankfurt: Iberoamericana, Vervuert.

Cortés, F. (director). (1961). Muchachas que trabajan (película). Nopal Filmes, 2005.

Cukor, G. (director). (1939). The Women (trailer). Consultado el 19 Mayo de 2011. Disponible en http://www.youtube.com/watch?v $=\mathrm{dZ}$ V0k77ih8Q

Curtiz, M. (director). (1945). Mildred Pierce (película). Keepcase, 2006.

Franco, J. (1993). Las conspiradoras: la representación de la mujer en México. México: El Colegio de México, Fondo de Cultura Económica.
García Riera, E. (1986). Julio Bracho, 1909-1978. México: Universidad de Guadalajara, Centro de Investigaciones y Enseñanza Cinematográficas.

Gómez Muriel, E. (director). (1948). Nosotras las taquigrafas (película). Colección México en Pantalla.

Hershfield, J. (2008). Imagining la Chica Moderna: Women, Nation, and Visual Culture in Mexico, 1917-1936. Durham-Londres: Duke University Press.

Instituto de Estudios Educativos y Sindicales de América, (IEESA) (2012). Los movimientos de mujeres y su incidencia en la participación sindical en México. Ciudad de México: Sindicato Nacional de Trabajadores de la Educación.

Lahr-Vivaz, E. (2016). Mexican Melodrama: Film and Nation from the Golden Age to the New Wave. Tucson: The University of Arizona Press.

Lauretis, T. de (1984). Alice Doesn't: Feminism Semiotics Cinema. Bloomington: Indiana University Press.

López, A. M. (2004). Tears and Desire: Women and Melodrama in the 'Old' Mexican Cinema. The Latin American Cultural Studies Reader.
Durham and London: Duke University Press, 441-458.

Monsiváis, C. (1992). Las mitologías del cine mexicano. Intermedios, 2, 12-23.

Mora, C. J. (2005). Mexican cinema: Reflections of a Society, 1896-2004. Jefferson: McFarland Company.

Moreno, A. (director). (1931). Santa (película) Colección México en Pantalla.

Orellana, C. (director). (1943). Arriba las mujeres (película). Burbank: Warner Home Video.

Rich, A. (1986). Of Woman Born. Nueva York: Norton.

Sánchez Prado, I. (2014). Regimes of Affect Love and Class in Mexican Neoliberal Cinema. Journal of Popular Romance Studies, 4(1). Retrieved from http://jprstudies. org/wp-content/uploads/2014/01/ROALACIMNC_SanchezPrado.pdf

Tuñón, J. (1998). Mujeres de luz y sombra en el cine mexicano: la construcción de una imagen (1939-1952). México: El Colegio de MéXiCO, IMCINE.

Tuñón, J. (2015). Mujeres: entre la imagen y la acción. México: CONACULTA. 